Supporting information

\title{
Unsymmetrical Squaraine Dye-Based Organic Photodetector Exhibiting Enhanced Near Infrared Sensitivity
}

\author{
Guruprasad M. Somashekharappa ${ }^{\mathrm{a}, \mathrm{b}}$, Chinju Govind ${ }^{\mathrm{a}, \mathrm{b}}$, Vijith K. P.c, Megha \\ Paula $^{\mathrm{a}, \mathrm{b}}$, Manoj A. G. Namboothiryc, ${ }^{\mathrm{c},}$, Suresh Das ${ }^{\mathrm{d}, *}$, Venugopal Karunakaran ${ }^{\mathrm{a}, \mathrm{b},{ }^{*}}$
}

aPhotosciences and Photonics Section, Chemical Sciences and Technology Division, CSIRNational Institute for Interdisciplinary Science and Technology, Thiruvananthapuram-695 019, Kerala, India, bAcademy of Scientific and Innovative Research (AcSIR), Ghaziabad- 201002, India, 'School of Physics, Indian Institute of Science Education and Research Thiruvananthapuram, Thiruvananthapuram-695551, Kerala, India, dSchool of Chemistry, Indian Institute of Science Education and Research Thiruvananthapuram, Thiruvananthapuram-695551, Kerala, India. 
Scheme S1 Synthetic scheme of ANPHSQ derivative. S3

General procedure for synthesis of ANPHSQ derivative. $\quad$ S4

Figure S1 Steady state absorption and emission spectra of ANPHSQ in solvents $\quad$ S8 of various polarities at room temperature.

Figure S2 Fluorescence spectra of ANPHSQ obtained upon excitation at $700 \mathrm{~nm} \quad$ S9 in the thin film made from $\mathrm{CHCl}_{3}$.

Figure S3 (a) Cyclic voltammogram of ANPHSQ in ACN using tetrabutyl ammonium hexafluorophosphate as supporting electrolyte at a scanning rate of $50 \mathrm{mV} / \mathrm{sec}$.

(b) HOMO and LUMO levels of ANPHSQ vs PCBM.

Figure S4 Femtosecond transient absorption spectra of ANPHSQ in ACN in the shorter (a) and longer wavelength region (b) at different time delays upon $670 \mathrm{~nm}$ excitation.

Figure S5 Femtosecond transient absorption decay of ANPHSQ in toluene and ACN (a), transient decay (b) and bleach recovery (c) of ANPHSQ with and without PCBM in toluene upon excitation at $670 \mathrm{~nm}$.

Figure S6 Femtosecond transient absorption spectra of ANPHSQ with PCBM in toluene in the shorter (a) and longer wavelength region (b) at different time delays upon $670 \mathrm{~nm}$ excitation.

Figure S7 Decay associated spectra of ANPHSQ in ACN and toluene with and without PCBM obtained using global analysis upon $670 \mathrm{~nm}$ excitation.

Table S1 Electrochemical data of ANPHSQ obtained from cyclic voltammetry in ACN. 
a. Synthesis of semisquaraine

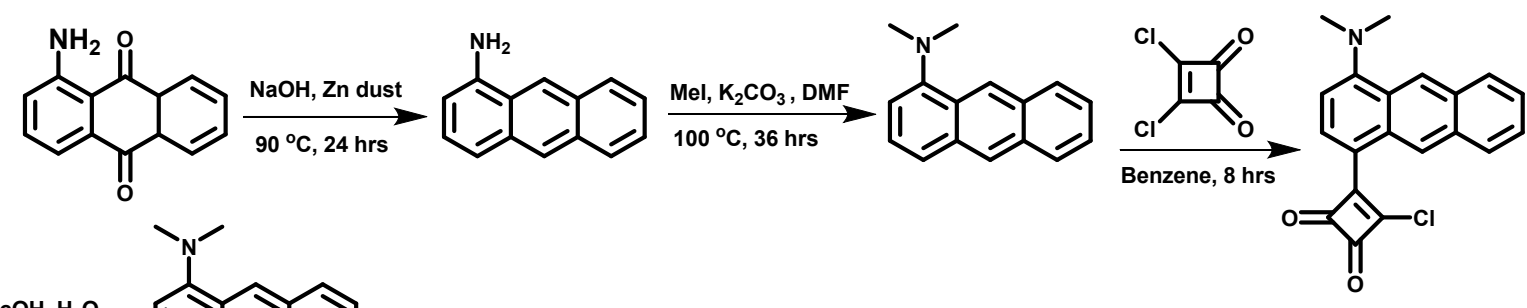

$$
\mathrm{AcOH}, \mathrm{H}_{2} \mathrm{O}
$$<smiles>[C]1=C[C]=C1</smiles><smiles>CC1=C(O)C(=O)C(=O)C1</smiles>

b. Synthesis of nucleophiles

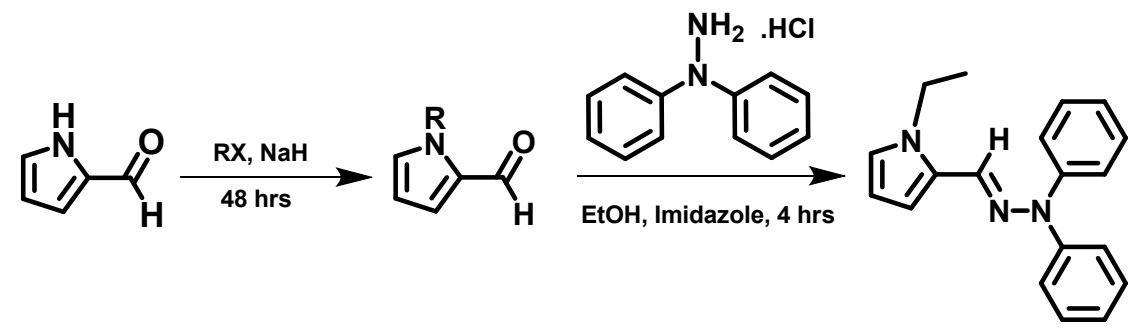

c. Coupling between semisquaraine and nucleophiles
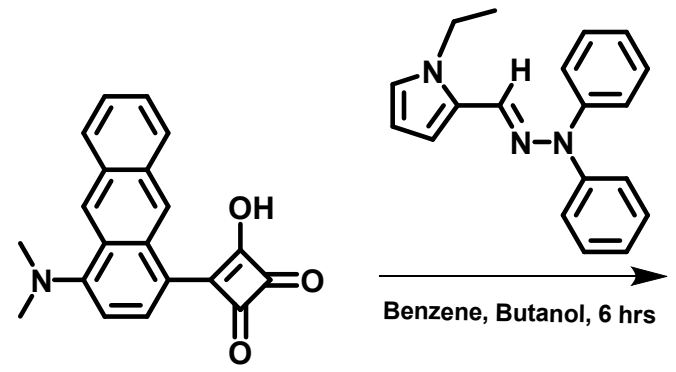<smiles>CC[N+]1=C(/C=N/N(c2ccccc2)c2ccccc2)C=C/C1=C1/C(=O)C(c2ccc(N(C)C)c3cc4ccccc4cc23)=C1[O-]</smiles>

Scheme S1 Synthetic scheme of ANPHSQ derivative. 


\section{General procedure for synthesis of ANPHSQ derivative}

\subsection{Synthesis of 1-Aminoanthracene}

1-Aminoanthraquinone $(5 \mathrm{~g})$ was stirred with $10 \%$ sodium hydroxide $(60 \mathrm{ml})$ and zinc dust $(5 \mathrm{~g})$ at room temperature for about $30 \mathrm{~min}$. It was slowly heated to $85-90^{\circ} \mathrm{C}$. Zinc dust $(5 \mathrm{~g})$ was then introduced into the reaction mixture in two equal proportions at an interval of 30 minutes each and heating was continued with constant stirring for $24 \mathrm{~h}$, at $90^{\circ} \mathrm{C}$. After cooling, the solid material from the reaction mixture was collected and washed several times with water. Soxhlet extraction with acetone and then recrystallization from ethanol gave 1-aminoanthracene $(2.8 \mathrm{~g}, 65 \%)$.

${ }^{1}$ H NMR (500 MHz, $\left.\mathbf{C D C l}_{3}\right): \delta 8.71(\mathrm{~s}, 1 \mathrm{H}), 8.39(\mathrm{~s}, 1 \mathrm{H}), 8.03-7.99(\mathrm{t}, 2 \mathrm{H}, J=1 \mathrm{~Hz}), 7.47-7.42$ (m,2H), 7.39-7.37 (d,1H, $J=8.5 \mathrm{~Hz}), 6.76-6.74(\mathrm{~d}, 1 \mathrm{H}, J=7 \mathrm{~Hz}), 7.37-7.24(\mathrm{dd}, 1 \mathrm{H}, J=7 \mathrm{~Hz})$.

HRMS-EI: Calculated molecular weight for $\mathrm{C}_{14} \mathrm{H}_{11} \mathrm{~N}$ is 193.24, Found $=194.0962$.

\subsection{Synthesis of N, N-dimethylanthracen-1-amine}

1-Aminoanthracene $(1.4 \mathrm{~g}, 7.24 \mathrm{mmol})$ and activated potassium carbonate $(6.9 \mathrm{~g}, 50.68$ mmol) was taken in a $250 \mathrm{ml}$ round bottomed flask. It was stirred in $20 \mathrm{ml}$ of dry dimethyl formamide (DMF). Then the pressure equalizing funnel was connected between RB flask and condenser. To that $10 \mathrm{ml}$ of DMF and methyl iodide (5.1g, $36.22 \mathrm{mmol})$ was added. Then this mixture was slowly added to the RB flask, it was stirred for about an hour in the room temperature. Then the reaction mixture was heated at $100{ }^{\circ} \mathrm{C}$ for about $36 \mathrm{hrs}$. After the reaction, the mixture is allowed to cool to the room temperature and then transferred to a beaker containing ice. The organic phase was extracted with dichloromethane and it was washed several times with water, dried over sodium sulphate. Then the solvent is removed under reduced 
pressure. The product was purified by column chromatography [silica gel, hexane: ethyl acetate (3:97)] to give a green viscous oil $(1.1 \mathrm{~g}, 69 \%)$.

${ }^{1} \mathbf{H}$ NMR (500 MHz, CDCl $): \delta 8.79(\mathrm{~s}, 1 \mathrm{H}), 8.39(\mathrm{~s}, 1 \mathrm{H}), 8.06-8.04(\mathrm{t}, 1 \mathrm{H}, J=4.5 \mathrm{~Hz}), 7.99-7.97$ (t,1H, $J=4.5 \mathrm{~Hz}), 7.46-7.44(\mathrm{~m}, 2 \mathrm{H}), 7.69-7.67(\mathrm{~d}, 1 \mathrm{H}, J=8.5 \mathrm{~Hz}), 7.39-7.36(\mathrm{dd}, 1 \mathrm{H}, J=7 \mathrm{~Hz})$, 7.02-7.01 (d, $1 \mathrm{H}, J=7 \mathrm{~Hz}), 2.99(\mathrm{~s}, 6 \mathrm{H})$. HRMS-EI: Calculated molecular weight for $\mathrm{C}_{16} \mathrm{H}_{15} \mathrm{~N}$ is 221.30, Found $=222.0913$.

\subsection{Synthesis of 3-(4-(dimethylamino) anthracen-1-yl)-4-hydroxycyclobut-3ene1, 2dione}

3, 4-dichlocyclobutene-1,2 dione (commonly called squarylium chloride, $0.73 \mathrm{~g}, 4.9$ $\mathrm{mmol})$, and $\mathrm{N}, \mathrm{N}$ - dimethylanthracen-1-amine $(1.1 \mathrm{~g}, 4.9 \mathrm{mmol})$, were dissolved in dry benzene $(30 \mathrm{ml})$ and refluxed for $8 \mathrm{hrs}$. After cooling the reaction mixture, the solvent was removed under reduced pressure and the crude product obtained was dissolved in a mixture of glacial acetic acid $(15 \mathrm{ml})$, distilled water $(15 \mathrm{ml})$ and $2 \mathrm{~N} \mathrm{HCl}(10 \mathrm{ml})$. The resulting mixture was then refluxed for $2 \mathrm{hrs}$ at $120^{\circ} \mathrm{C}$. After cooling, the solution was added to a crushed ice, the precipitated product thus obtained was isolated by filtration, washed with diethyl ether and dried. (0.85 g, 35\%). The blackish brown powder obtained was used without further purification.

HRMS-EI: Calculated molecular weight for $\mathrm{C}_{20} \mathrm{H}_{15} \mathrm{O}_{3}$ is 317.34 , Found $=318.1131$

\subsection{Synthesis of 1-ethyl-1H-pyrrole-2-carbaldehyde}

A solution of pyrrole 2-carbaldehyde $(4 \mathrm{~g}, 42 \mathrm{mmol})$ in anhydrous dimethyl formamide (DMF,20ml) was added drop wise at $0{ }^{\circ} \mathrm{C}$ and under nitrogen to a suspension of sodium hydride (NaH, 60\% suspension in mineral oil, $1.41 \mathrm{~g} 58.8 \mathrm{mmol}$ ) in the same solvent. The resulting suspension was stirred at $0{ }^{\circ} \mathrm{C}$ for 30 minutes, and a solution of ethyl iodide $(7.2 \mathrm{~g}, 46.2 \mathrm{mmol})$ in 
anhydrous DMF $(5 \mathrm{ml})$ was added drop wise. The suspension was stirred for $48 \mathrm{hrs}$ at room temperature and then poured into Brine and extracted with diethyl ether. The organic phase was washed with water, dried over anhydrous sodium sulphate and filtered. The crude product thus obtained was purified by column chromatography (silica gel, hexane: ethyl acetate, 3:97) to give a yellow oil $(2.2 \mathrm{~g}, 44 \%)$.

${ }^{1}$ H NMR (500 MHz, CDCl $): \delta 9.53$ (s, 1H), $6.96(\mathrm{~s}, 1 \mathrm{H}), 6.23-6.21$ (dd,1H, $\left.J=2 \mathrm{~Hz}\right), 6.93-6.92$ $(\mathrm{dd}, 1 \mathrm{H}, J=2 \mathrm{~Hz}), 4.37-4.33(\mathrm{q}, 2 \mathrm{H}, J=7.5 \mathrm{~Hz}), 1.40-1.37(\mathrm{t}, 3 \mathrm{H})$

\subsection{Synthesis of (E)-2-((2,2-diphenylhydrazono)methyl)-1-ethyl-1H-pyrrole}

A mixture of N, N-diphenylhydrazine hydrochloride (2.67 g, $12.18 \mathrm{mmol})$, 1-ethyl-1Hpyrrole-2-carbaldehyde $(1.5 \mathrm{~g}, 12.18 \mathrm{mmol})$ and imidazole $(0.82 \mathrm{~g}, 11.16 \mathrm{mmol})$ was dissolved in anhydrous ethanol $(30 \mathrm{ml})$, and refluxed for $4 \mathrm{hrs}$. After the reaction, the mixture is allowed to cool to room temperature, then the solvent was removed under reduced pressure and the residue was purified by column chromatography (silica gel, hexane: ethyl acetate, $85: 15$ ) to give a yellow viscous oil. $(2.67 \mathrm{~g}, 43 \%)$.

${ }^{1} \mathbf{H}$ NMR (500 MHz, CDCl $): \delta 6.72-6.71(\mathrm{t}, 1 \mathrm{H}, J=2.5 \mathrm{~Hz}), 6.1-6.08(\mathrm{dd}, 1 \mathrm{H}, J=3 \mathrm{~Hz}), 6.14-$ $6.13(\mathrm{dd}, 1 \mathrm{H}, J=2 \mathrm{~Hz}), 7.13-7.10(\mathrm{~m}, 4 \mathrm{H}), 7.41-7.31(\mathrm{~m}, 4 \mathrm{H}), 7.16-7.15(\mathrm{~m}, 2 \mathrm{H}), 4.47-4.30(\mathrm{q}, 2 \mathrm{H}$, $J=7.5 \mathrm{~Hz}), 1.50-1.47(\mathrm{t}, 3 \mathrm{H})$.

\subsection{Synthesis of ANPHSQ ((E)-2-(3-(4-(dimethylamino) anthracen-1-yl)-2-hydroxy-4 oxocyclobut-2-en-1-ylidene)-5-((Z)-(2,2-diphenylhydrazono)methyl)-1-ethyl-2H- pyrrol-1 ium}

A mixture of $1 \mathrm{c}(0.2 \mathrm{~g}, 0.6 \mathrm{mmol})$, and the hydrazone precursor, $1 \mathrm{e}(0.17 \mathrm{~g}, 0.6 \mathrm{mmol})$ was dissolved in a 1:1 benzene: butanol azeotropic mixture $(30 \mathrm{ml})$, and refluxed at $90{ }^{\circ} \mathrm{C}$ in a DeanStark apparatus for about 8 hrs. After the reaction, the mixture is allowed to cool to room temperature and then the solvent is removed under reduced pressure. Then the residue was 
purified by column chromatography. (silica gel, hexane: ethyl acetate, 60:40), followed by recrystallization with chloroform. (0.140 g, 38\%).

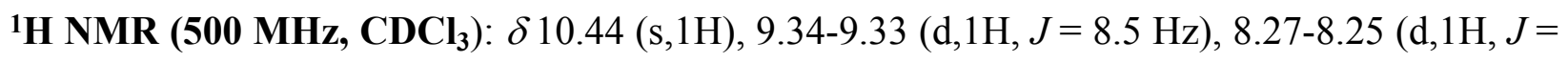
8.5 Hz), 8.03-8.02 (d, 1H, $J=4.5 \mathrm{~Hz}), 7.98-7.96(\mathrm{~d}, 1 \mathrm{H}, J=8.5 \mathrm{~Hz}), 7.55-7.47(\mathrm{~m}, 6 \mathrm{H}), 7.31-$ $7.26(\mathrm{~m}, 2 \mathrm{H}), 7.23-7.21(\mathrm{~m}, 4 \mathrm{H}), 7.12(\mathrm{~s}, 1 \mathrm{H}), 6.94-6.93(\mathrm{~d}, 1 \mathrm{H}, J=8.5 \mathrm{~Hz}), 6.86-6.85(\mathrm{~d}, 1 \mathrm{H}, J=$ $4.5 \mathrm{~Hz}), 5.03-4.99$ (q, 2H, $J=7 \mathrm{~Hz}), 3.31(\mathrm{~s}, 6 \mathrm{H}), 1.44-1.41$ (t, 3H). FTIR, (KBr Pellet, $\left.\mathbf{c m}^{-1}\right)$ : 2340. HRMS-EI: Calculated molecular weight for $\mathrm{C}_{39} \mathrm{H}_{32} \mathrm{~N}_{4} \mathrm{O}_{2}$ is 588.70 , Found $=588.2530$. 


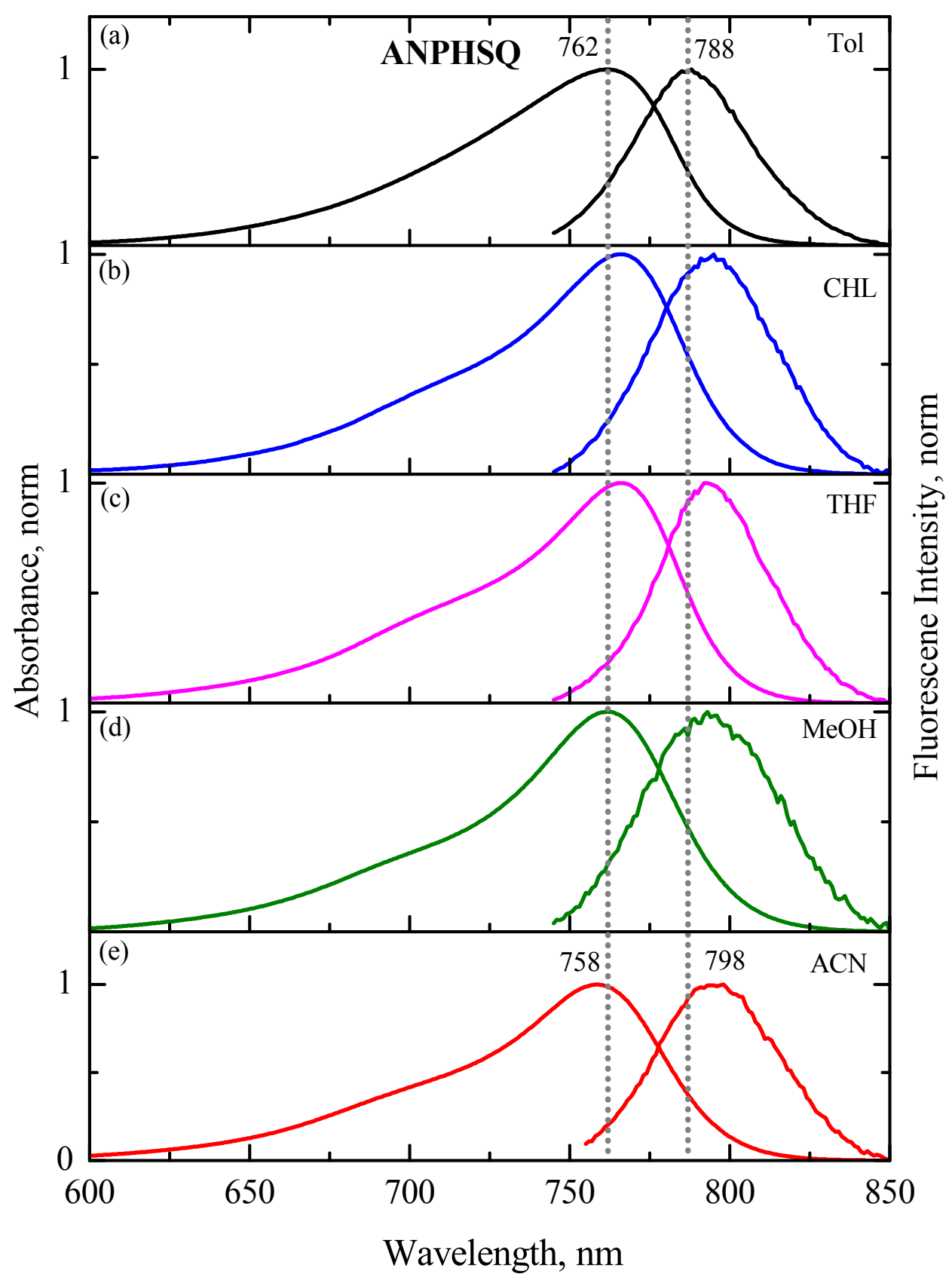

Figure S1 Steady state absorption and emission spectra of ANPHSQ in solvents of various polarities at room temperature. 


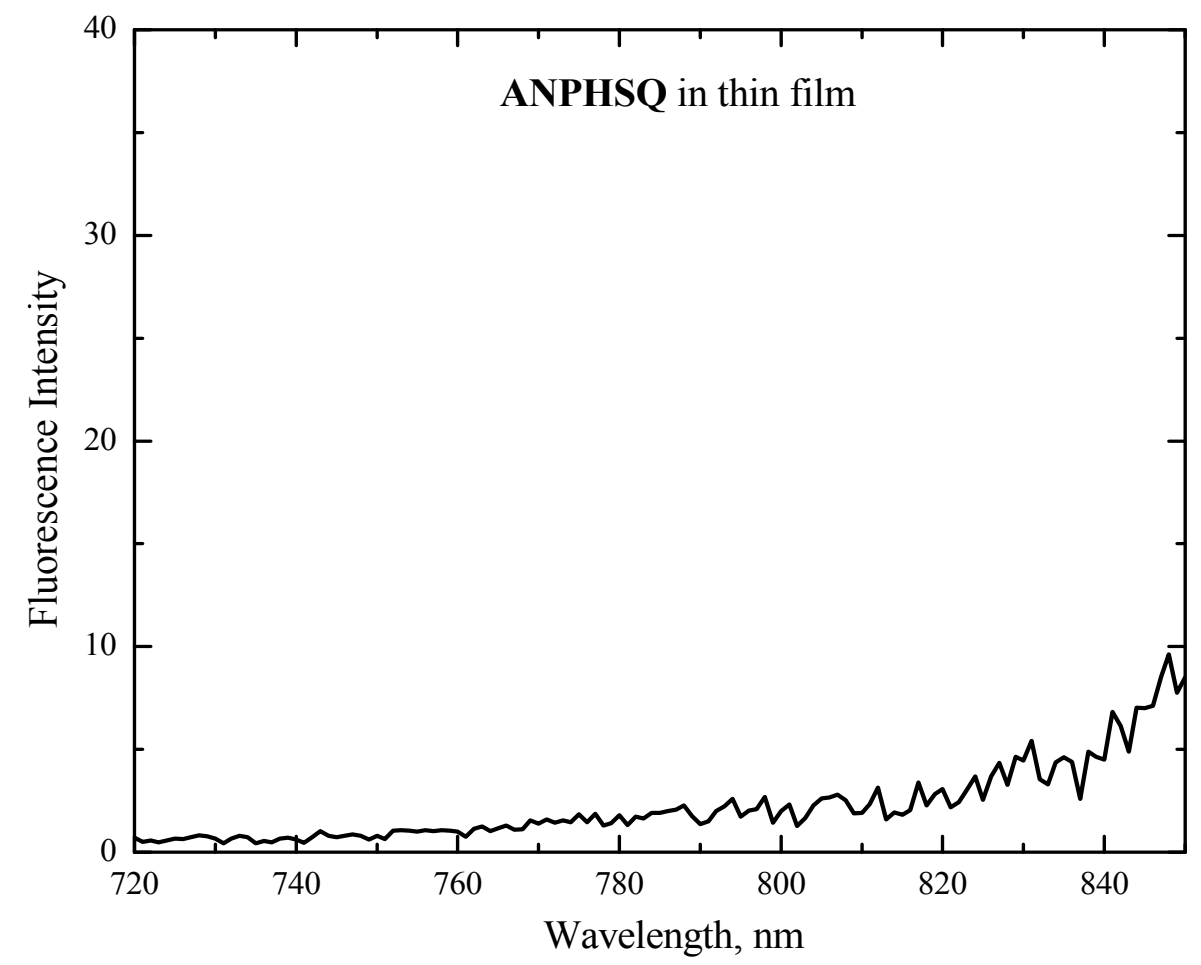

Figure S2 Fluorescence spectra of ANPHSQ obtained upon excitation at $700 \mathrm{~nm}$ in the thin film made from $\mathrm{CHCl}_{3}$. 

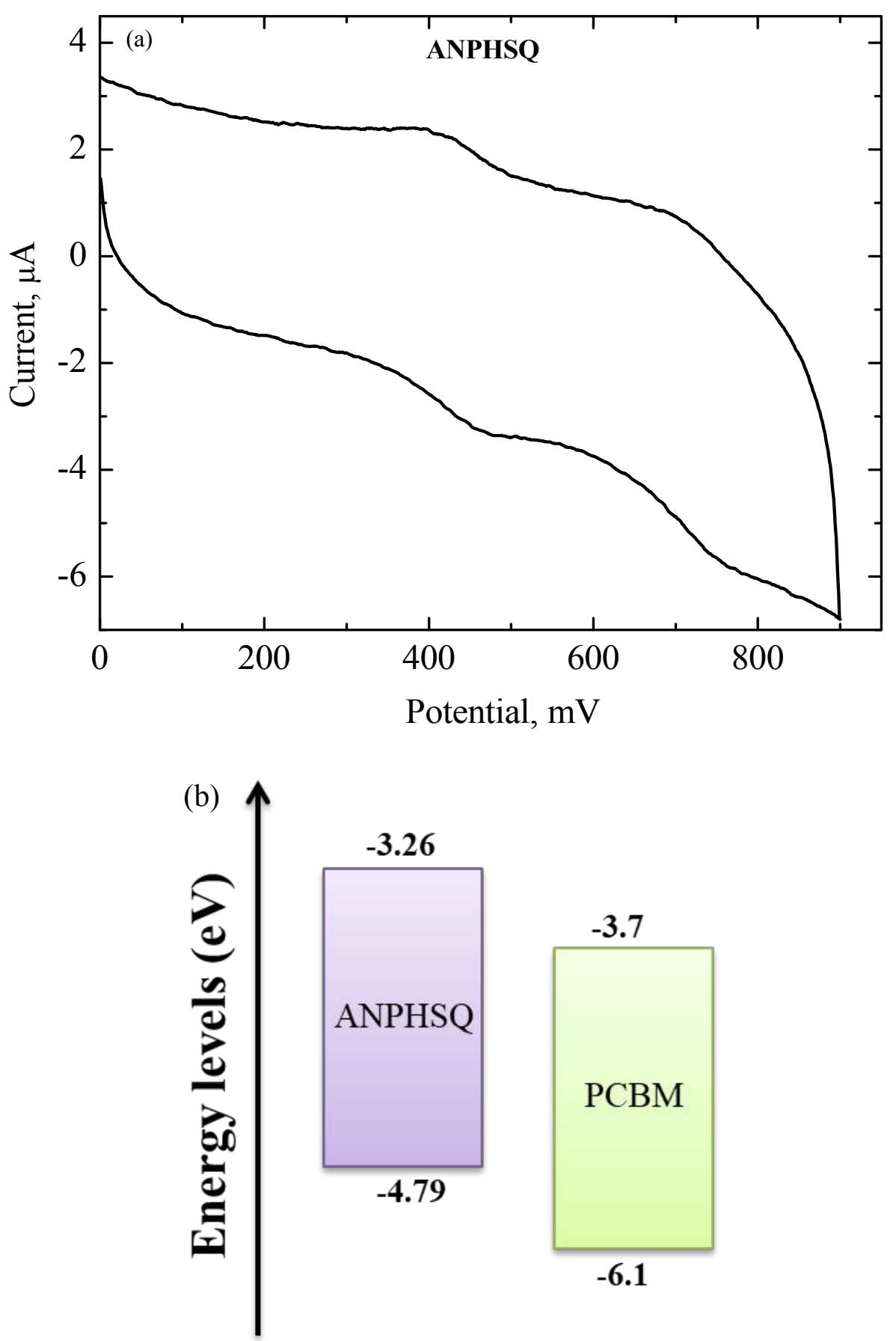

Figure S3 Cyclic voltammogram of ANPHSQ in ACN using tetrabutyl ammonium hexafluorophosphate as supporting electrolyte at a scanning rate of $50 \mathrm{mV} / \mathrm{sec}$ (a). HOMO and LUMO levels of ANPHSQ vs PCBM (b). 

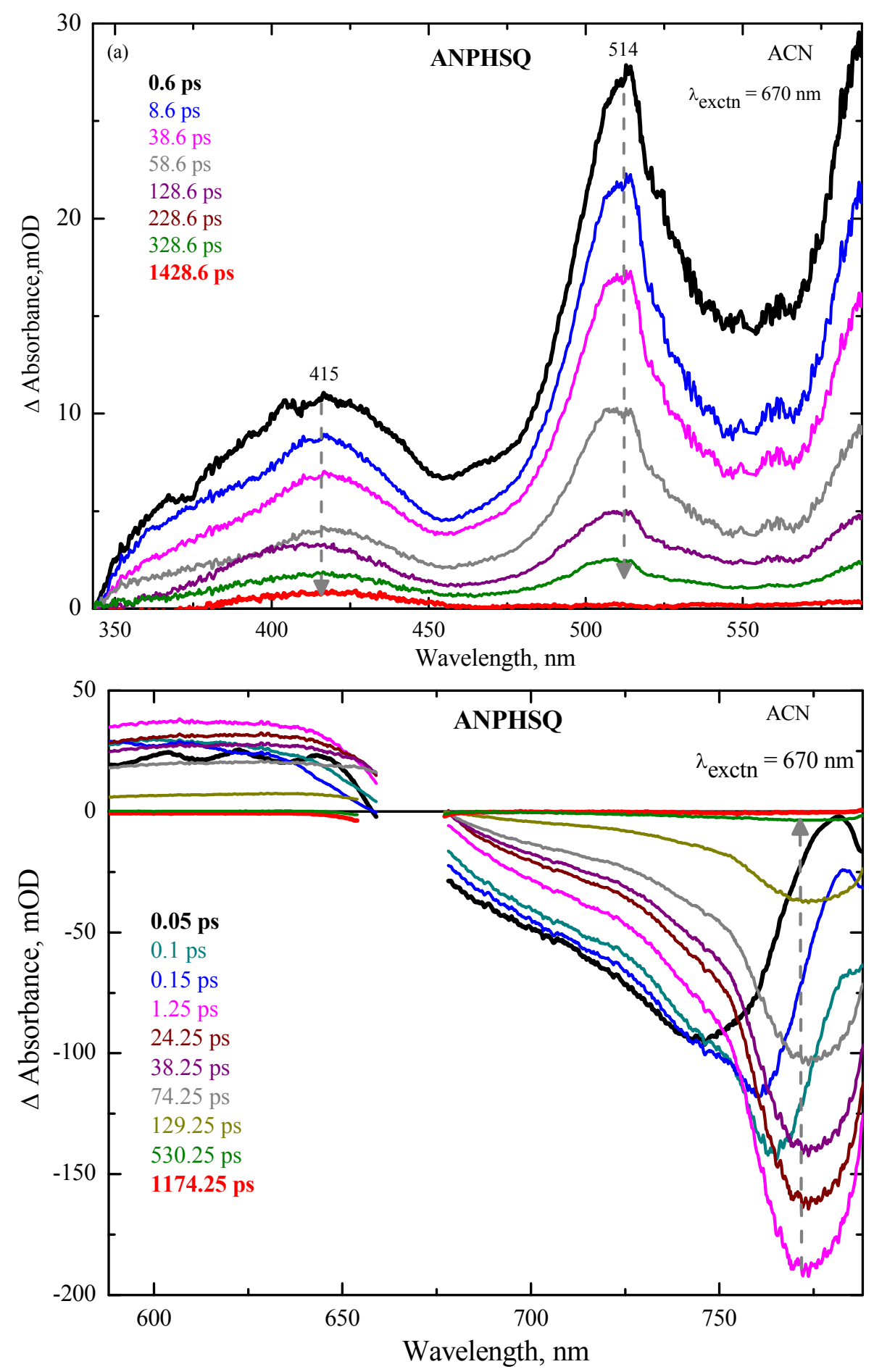

Figure S4 Femtosecond transient absorption spectra of ANPHSQ in ACN in the shorter (a) and longer wavelength region (b) at different delay times upon $670 \mathrm{~nm}$ excitation. 


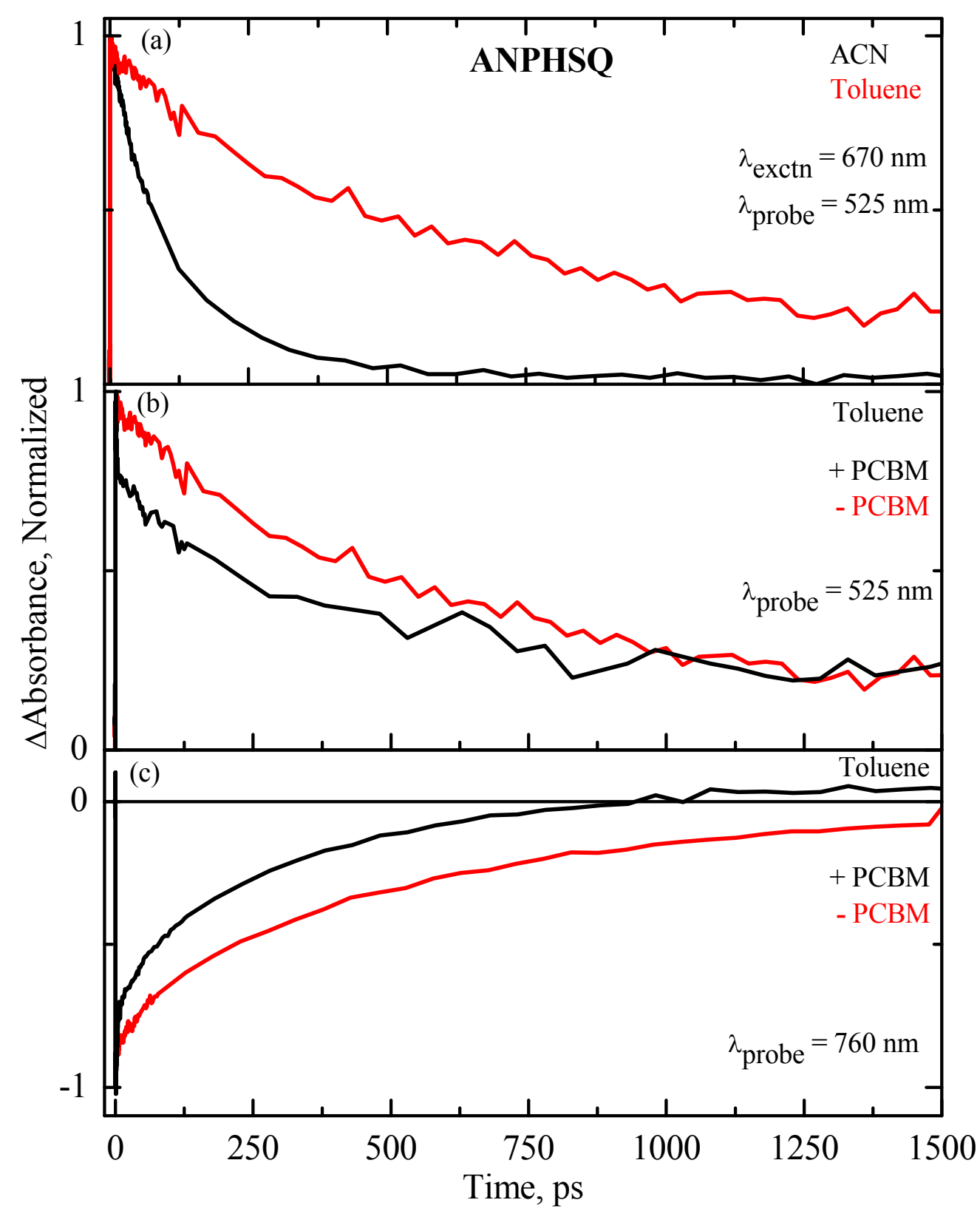

Figure S5 Femtosecond transient absorption decay of ANPHSQ in toluene and ACN (a), transient decay (b) and bleach recovery (c) of ANPHSQ with and without PCBM in toluene upon excitation at $670 \mathrm{~nm}$. The probe wavelengths are given in the insets. 

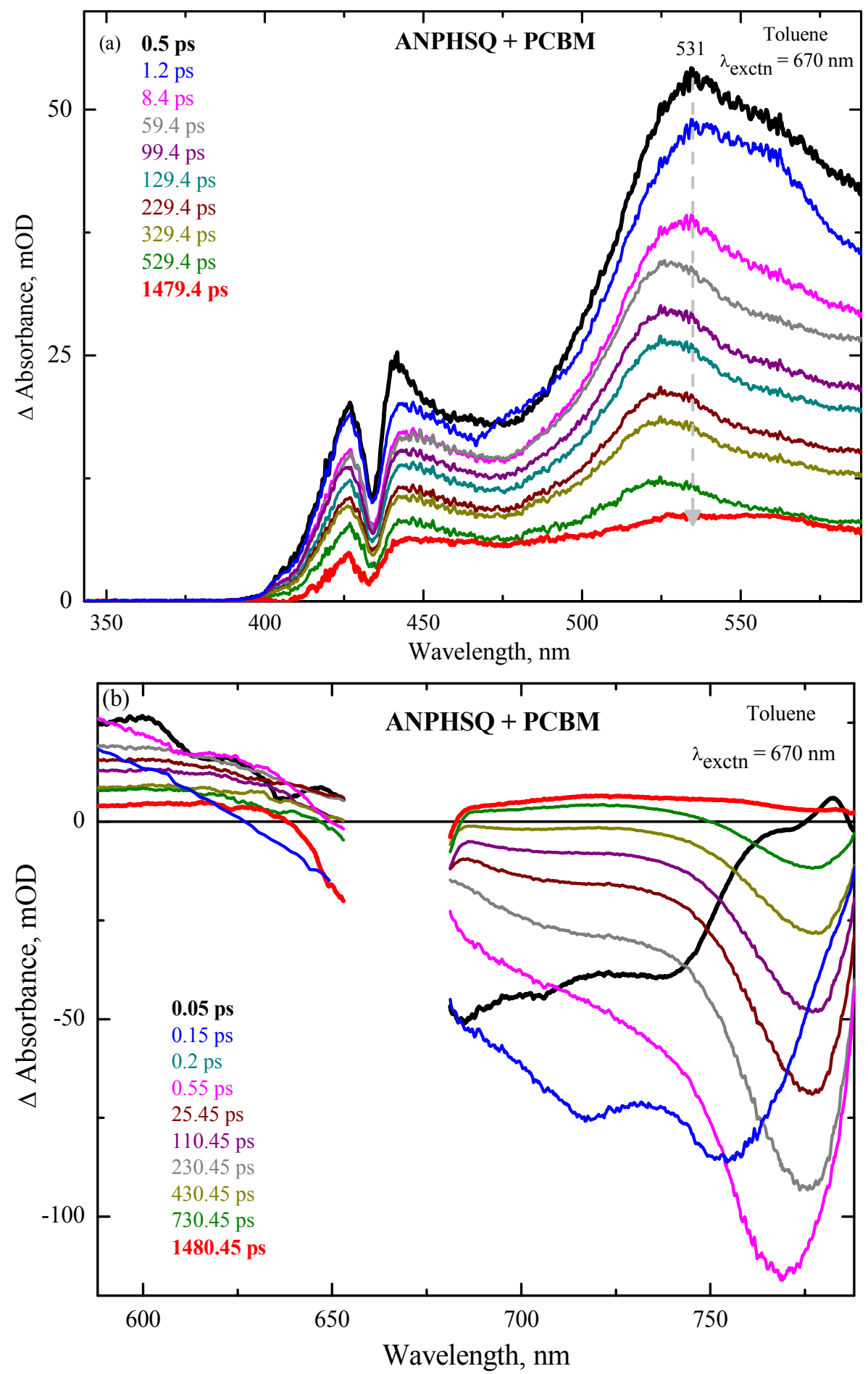

Figure S6 Femtosecond transient absorption spectra of ANPHSQ with PCBM in toluene in the shorter (a) and longer wavelength region (b) at different delay times upon $670 \mathrm{~nm}$ excitation. 


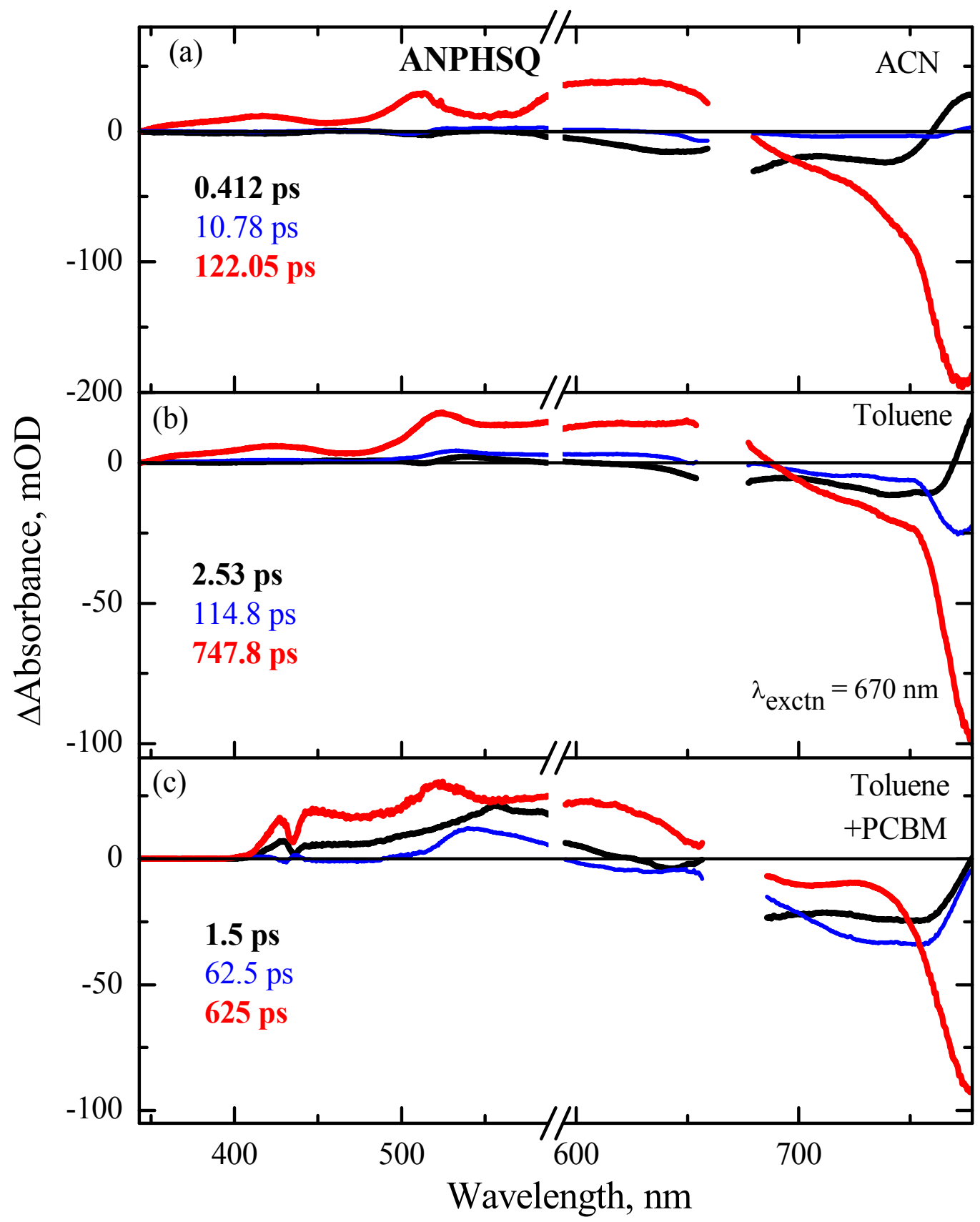

Figure S7 Decay associated spectra of ANPHSQ in ACN, toluene and with PCBM obtained by using global upon $670 \mathrm{~nm}$ excitation. 
Table S1 Electrochemical data of ANPHSQ from cyclic voltammetry in ACN.

\begin{tabular}{ccccc}
\hline $\begin{array}{c}\lambda_{\mathbf{0 0}} \\
(\mathbf{n m})\end{array}$ & $\begin{array}{c}\mathbf{E}_{\mathbf{0 0}} \\
(\mathbf{e V})\end{array}$ & $\begin{array}{c}\mathbf{E}_{\mathbf{0 x}} \text { vs. Ag/AgCl } \\
(\mathbf{V})\end{array}$ & $\begin{array}{c}\text { HOMO } \\
(\mathbf{e V})\end{array}$ & $\begin{array}{c}\text { LUMO } \\
(\mathbf{e V})\end{array}$ \\
\hline & & & & \\
810 & 1.53 & 0.43 & -4.79 & -3.26 \\
\hline
\end{tabular}

